\title{
Analysis of Effective Instructional Sequences in Upper Primary Education (11-12 Years Old Students) to Enhance Content-Learning through the Integrated Use of Reading and Writing
}

\author{
Isabel Martínez, Mar Mateos and Elena Martín
}

Theoretical Background

The society in which we find ourselves offers large amounts of information. The messages which we receive come from a number of different and varying sources, that are at times complementary and at other times contradictory. For that reason, it is necessary to compare, contrast and integrate these sources in order to transform the information into knowledge (Pozo \& Postigo, 2000). With this in mind, it is important to teach students how to create written syntheses of information from a number of different texts. However, there are very few studies that have proposed teaching the necessary strategies for creating these syntheses. Furthermore, the majority of the studies that have been conducted have been carried out in higher education settings (Boscolo, Arfé \& Quarisa, 2007; Segev-Miller, 2004).

Therefore, the Strategies for Writing Syntheses to Learn ( $S W s L)$ program presented in this chapter has been designed to teach students of 11-12 years old how to appropriately use reading and writing as tools in learning the content which the texts aim to convey. It deals with a program focused on the teaching strategies involved in the elaboration of a written synthesis of various texts. The advantages of this type of instruction, both with reading and writing (Graham \& Harris, 1996; Mateos, 2001; Sánchez, García \& Rosales, 2010; Schunk \& Zimmerman, 1997; Torrance, Fidalgo \& García, 2007; Zimmerman, 2000), as

Martínez, I., Mateos, M., \& Martín, E. (2017). Chapter 8: Analysis of Effective Instructional Sequences in Upper Primary Education (11-12 Years Old Students) to Enhance ContentLearning through the Integrated Use of Reading and Writing. In R. Fidalgo \& T. Olive (Series Eds.) \& R. Fidalgo, K.R. Harris, \& M. Braaksma, (Vol Eds.), Studies in Writing Series: Vol. 34. Design Principles for Teaching Effective Writing, (pp. ). Leiden: Brill. 
well as the integrated use of both of them (Raphael \& Englert, 1990; Wray \& Lewis, 1997), have been widely studied.

In this way, the specific objective is that the students learn to read and write by selecting, elaborating, connecting and integrating the information coming from different texts with the goal of learning these contents in a profound and constructive way.

The $S W S L$ program (that can be carried out by the student's teachers themselves if they have received prior training) focuses on strengthening the development of the strategies involved in the process of a synthesis through diverse teaching methods. The strategies taught through this intervention are: (1) selecting important ideas from the source texts, (2) elaborating upon the information using prior knowledge, (3) organizing the content, and (4) integrating information from both source texts.

Through different teaching methods, based on the progressive transfer of control, autonomy and self-regulation of the learning process is encouraged amongst students. Based on previous studies (Wray \& Lewis, 1997), all the strategies are taught using a variety of methods, such as (1) teacher modelling, (2) collaborative activity, (3) guided activity, (4) students' individual activity and (5) the support of a written guide. Thanks to the implementation of this $S W S L$ program, the students are able to achieve a number of important goals, which will be described throughout the chapter, that provide them with a quality learning experience.

\section{The Phases of the Program}

The $S W S L$ program consists of 12 sessions that are divided into three phases. In each phase, a different synthesis task is carried out, thereby offering an increasing degree of control to the students as the program progresses. At the end of the program the students carry out the last task on their own and all prior offers of help or assistance are removed. Two expositive texts-including complementary contents about the treated subject - of similar length (235280 words) were selected for each synthesis task. All texts were provided from different textbooks directed towards 11-12 years old students and they belonged to the same teaching unit (contemporary history). In Table 8.1-and in the additional documents placed on the following link: www.figshare.com-the stages of the $S W S L$ program are described in detail as well as the objectives, contents, activities of both the students and the teacher, the teaching methods, materials, etc. used in each one. As can be seen, the intervention follows a progressive sequence of transfer of control of the learning process, from the instructor to the students, in the hopes of encouraging self-regulation amongst the students through their increased awareness of the processes that 
are activated during the learning process. In this way, throughout the stages there is a decrease in the number of activities carried out by the teacher and an increase in number of activities that the student are in charge of themselves. Additionally, the students write in a collaborative way in order to assist with the transition between the phases of modelling by the teacher and that of working on their own.

\section{Description of the Phases in the swsL Program}

The following describes in detail each of the steps of the $S w S L$ program. In order to provide greater clarity, the explanation and justification is presented in a sequential manner. However, it is important to keep in mind that this process is actually complex and recursive.

\section{Synthesis Task Representation}

We begin the first session by working on the representation the students have of the synthesis task. It is important to explore the students' prior knowledge about what creating a synthesis is (the cognitive aspect) and what it is useful for (the motivational aspect), as they will perform the task differently depending on their individual representations of the task. Different studies have shown that students tend to simplify the representation they have of the synthesis task, assuming that it is similar to the task of summarizing, as this is a task with which they are more familiar (Flower et al., 1990; Mateos \& Solé, 2009). Additionally, our goal is to have the entire group share the same objectives.

Our premise is based on the idea that a direct description of the goals of this task by the instructor is not enough to enable students to create their own representations of the objectives. Therefore, students are encouraged to reflect and explore in order to become more aware of the goals of the task. To begin, students are told that they are going to learn to create a synthesis. Then, a debate might be started by asking them some questions related to the synthesis task, such as, "what do you think a synthesis is?", "Is this task easy or difficult for you?". However, from our experience we know how difficult it is for students to recognize and activate their previous knowledge when confronted with a learning task. On one occasion when we asked students these questions, we found that they replied, “I don't know anything”. Of course, this was not true, but it pointed out the importance of finding a resource that allow us to access that information. Since the students appeared to not know anything about the synthesis task and were able to maintain a simplified representation of it, we decided to use a debate about a similar, and more familiar, task 
TABLE 8.1 Description of the aims, contents, activities, strategies and material of the $S W S L$ program

$s W S L$ program to improve the use of reading and writing to learn through synthesis tasks

Session/aim

Activation of the representation of a synthesis task

$(\operatorname{session} 1)$

\section{Contents}

Processes involved in completing a written synthesis from two texts
PHASE I:

To perform the first synthesis task through observation of the researcher modelling the processes employed

(sessions 2-5)

Elaboration of a guideline to help students to control their own processes (to be used in all sessions)

(session 5-continuation-)
Comprehension of the source texts, selection, elaboration, organization and integration of ideas in the creation of a synthesis text.

Steps to follow in creating a written synthesis from two sources 


\section{Instructor/student activities}

Instructor: Suggests questions such as "What is a synthesis?" "Is it similar to a summary?" "How can you create a good synthesis?"

Students: Present their ideas to the rest of the Guided questions class
Teaching methods

Brainstorming

Joint reflection

\section{Material}

replace by endash, ok?
Instructor: Presents and explains aloud all of their thought process while they carry out activities such as Reading the source tests, underlining, taking notes, creating concept maps, etc.

Students: Observe the instructor and take notes on all of the activities carried out by him/her

Instructor: Asks students to recall the activities that they have carried out previously to create a good synthesis. Using questions, they guide the process in order to recall all of the steps they have followed the previous sessions.

Students: Collectively reach an agreement regarding which activities should be carried out in order to create a synthesis. modelling by thinking

aloud strategy

Pair of texts about the industrial revolution

Self-questioning

\section{Self-instruction}

Guided questions

Joint reflection 
TABLE 8.1 The aims, contents, activities, strategies and material of the sws program (cont.)

$s w s L$ program to improve the use of reading and writing to learn through synthesis tasks

Session/aim

Contents

PHASE II:

To perform a second synthesis task performed in a group in order to provide students with slightly more autonomy than in the previous one

Comprehension of the source texts, selection, elaboration, organization and integration of ideas in the creation of a synthesis text.

(sessions 6-9)

\section{PHASE III:}

To perform a third synthesis task in which, with some assistance, the students, individually carry out the activities

(sessions 10-12)
Comprehension of the source texts, selection, elaboration, organization and integration of ideas in the creation of a synthesis text. 
Instructor: Responds to the questions of each group and offers help when they observe that one of the groups is experiencing difficulties. When absolutely necessary they assist with brainstorming.

Students: Emulate the activities explained by the instructor in the first group task with the support of the guide and the materials from prior sessions. Negotiate the best way to complete the written product as a group.
Collaborative work

Monitoring

Joint reflexion

Individual practice

Monitoring

Joint reflexion
Instructor: Responds to the questions proposed by the students and provides help when they observe that a student is experiencing difficulties with the task.

Proposes joint reflection when necessary.

Students: Carry out the entire synthesis task with the help of the guide, the instructor and the material created in the prior sessions.
Pair of texts about social and politic organization under capitalism

Written guide

Material created in phase I (concept maps, the first synthesis, etc.)
Pair of texts about rural and urban life in the 19th century

Written guide

Material created in the prior sessions 
in order to compare the processes involved in them: Instead, we asked questions about summary tasks, such as, "What is a summary?", "What do you find making summaries useful for?", "Are summarizing and synthesizing similar or different tasks?". Other ideas could be to recall a task performed in the past or discuss the aspects involved in creating the synthesis.

As a fundamental part of the synthesis representation, it is important for students to be aware of the processes involved in writing a synthesis: selection, elaboration, organization and integration. For example, when performing this type of tasks, some information is relevant, whereas other information is not relevant, and what information is relevant depends on our objectives. Something that is helpful to active these processes in students' minds is telling them that if a new student started at the school and read their synthesis, he or she would have to be able to take an exam on that subject using the information in the written synthesis. In this way, we help them to understand that the goal is to provide with their words the most essential information from the source texts in an organised and integrated way.

This step may be complicated because students do not usually ask themselves these questions. Instead, they perform the tasks their teacher asks them to do with their only objective being to get it right for the teacher, rather than wondering what is the actual purpose behind that particular activity. It is therefore essential to encourage students to stop and think about what they sought to achieve through reading and writing at that particular time.

\section{Elaboration of the First Synthesis through Instructor Modelling}

During sessions $2-5$, the instructor employs cognitive modelling to convey the entire process of creating a written synthesis from two source texts (an example of source texts could be seen in the complementary e-chapterAppendix 1-). Our approach, following previous interventions (Braaksma, Rijlaarsdam, van den Bergh \& van Hout-Wolters, 2004; Vidal-Abarca, 2002; Wray \& Lewis, 1997; Zimmerman \& Kitsantas, 2002), is based on the premise that learning by modelling could be a good starting point in helping students to become aware of the processes involved and internalize them. The actions that are modeled in this phase of the program are: activation of prior knowledge, global and local understanding of the source texts, selecting the main ideas, elaborating upon these, integrating the information, organizing the content of the synthesis and writing it. As well as constant review of what has been written up until that point.

One of our aims is that the students learn the contents in a real and significant way. For this, we have to make sure that they are able to use their prior knowledge about the topic at hand, so that they will link the new knowl- 
edge with what they already know. With this in mind, the instructor uses selfinstruction and self-questions to demonstrate the process that they follow. When they have created a list of knowledge regarding the subject matter, they proceed to give students the texts that they are going to work with and they read their titles aloud. They ask about what the students think the articles deal with and then continue on to skim the entire text, which allows students to develop a general idea of the sources. Good comprehension helps the students to link and integrate the information they are presented with (Risenberg, 1996; Spivey \& King, 1989). This comprehension of the texts not only refers to the contents, but also to the structure, the purpose, the audience it is directed towards, etc. With this in mind, the instructor reflects on why the text is organized in such a way, and if it is adequate or could be modified in some way.

Next, the text is re-read aloud in more detail. When the teacher reads a paragraph, they ask, "What does the author wants to convey to me here?". This process is then repeated with each of the following paragraphs in the source texts. It is essential that during this phase students learn to monitor their own degree of comprehension and therefore we must provide them with resources to implement in the event that they do not understand the texts. Skilled readers perform this action automatically (Anderson, 1980). However, less experienced readers must learn to be aware of when they do not understand something. By thinking aloud, students become aware of the process to follow when they are faced with a lack of comprehension. First, students may ask themselves if this information is necessary to achieve their objective and therefore if they should take steps to try to understand it. Second, they must decide between other alternative actions, such as continue reading to see if the author provides additional information that helps them to understand, re-read the entire text or part of it, consult the dictionary, etc.

This second reading uses self-instruction to aid in the selection of the ideas that will later be included in the synthesis. In order to do so, the instructor uses the techniques of highlighting and taking notes. They explain aloud why they select certain ideas and what notes they take in relation to their objectives. This moment is when they begin to introduce the process of elaboration, as they explain certain highlighted ideas and/or notes in their own words, integrating them with their prior knowledge. The students must learn the importance of going beyond the mere copying or paraphrasing of the information found in the texts in order to be able to transform their knowledge.

Here we present an example of modelling in this stage of the instructions, "I have to think how I could explain this idea so that, for example, a classmate who did not know anything about this subject could understand. I might have to change some words that are hard to understand. It was difficult for me to 
understand so I will explain it in my own words". At the same time, they will recall some of ideas activated at the beginning of the activity and relate them to the specific content of the texts.

In creating the synthesis, one fundamental aspect is that the students integrate the information from each text, as well as that which is found in both texts. We want to make sure the students are clear about the differences between integrating information and simply putting it together. Integration is going beyond the information we are given and transforming it into learned and meaningful knowledge. With this goal in mind, and with the intention to organize the information that the students will include in the synthesis text, the instructor creates a concept map on the board (see Appendix 1) for each of the texts (with the most relevant concepts grouped together), later creating one that integrates the ideas of both texts. At all times students clearly communicate their thought process and the actions they carry out by asking questions that they immediately answer such as, "What ideas are the most and least relevant?", "Is there a connection between them?", "Are some of them included within the others?", etc. The ideas are transformed, eliminated, completed and so on. Once finished, it is reviewed through questions such as, "Are all relevant ideas included?", “Does this seem like the best order in which to explain it?", etc. An affective teaching method is to list the ideas that are going to be included in the final text in order of priority.

At this point, the instructor expresses the questions aloud while at the same time writing the first version of the synthesis on the board. It includes information such as, "now I am going to title my synthesis which will help the reader to know what I am going to write", "I will start writing the overall idea I want to convey and then I'll write the rest in order of importance", "I also need to close things with a conclusion at the end", etc.

While writing, they also clearly express the ongoing review process through self-correcting questions such as, "Have I clearly expressed this idea?", "Have I managed to connect it with the next?". Upon completion of this piece of writing, the instructor reads aloud the entire product and corrects errors that they have detected, for example by removing some parts, modifying others, etc. After this first reading, in which some modifications have been made, the text is read once more, which allows them to review the suitableness of the text. At this point, the first synthesis is considered to be finished.

\section{Development of the Written Guidelines}

Some programs focused on strategic teaching of reading and writing include, in addition to instruction, the use of written guidelines in order to help the student to gradually acquire autonomy and be able to self-regulate their learning 
process (Gárate \& Melero, 2004). This type of aid has a number of advantages, such as, it makes the student aware of issues that they would not think of on their own, it allows for a more complex process by orienting the student and it avoids "cognitive overload" by encouraging concentration on specific aspects rather than on all of the issues at once (Castelló, 2002).

Our goal is that students benefit from this program now, as well as in the future when they are able to work on their own. In order to encourage students to self-regulate their learning process, we jointly develop a guide with them in which all aspects are posed in the form of a question. Some examples of phases that may be proposed in this material are: "What are our aims?", "What for?", "How can I make a map or scheme linking the thoughts in the texts?", etc. (see Appendix 2 at the end of this document and Appendix 3 of the e-chapter for a complete and interactive guide).

Using brainstorming and the questions from the guide, the instructor encourages students to recall the objectives worked upon in the previous sessions. In order to elaborate the written guide, the instructor asks the students what they have done during the other sessions to create a good synthesis. They record all of the student's contributions on the blackboard and then they complete the steps so that the students are aware of the detailed process they have followed. If they forget any of the steps, the instructor asks them about something related to it that they had done in that session. Once all the steps are clear, the instructor speaks a little about what each one involves and what the students have done to complete them. In their notebooks, the students write down the guide that the instructor has written out on the blackboard and the instructor explains to them that they could use it as a guide when they do a similar task in the future.

It is important to stress that the guide is not intended to be a fixed sequence of steps. Rather, as in the previous sessions, the process of reflecting on the questions should be ongoing.

\section{Development of the Second Synthesis through Group Work}

This phase of the $s w S L$ program, sessions 6-9, involves the creation of a synthesis by the students in groups of four. It is intended to provide a transition from the completion of the task by the instructor as a model to the students carrying out the task on their own. During this phase, students create a single product per group.

Research on joint writing has been extensive due to the awareness of the benefits that it provides. Writing in small groups is useful in that it promotes discussion among students that leads them to need to justify certain decisions that they make during the writing process (Castelló \& Milian, 1997). In this type 
of teaching method, the teacher's role is important as they serve to support and guide the process through questions that encourage reflection and discussion. Specifically, the use of this type of writing (collaborative) offers a number of advantages: (1) it facilitates planning and review (since different alternatives usually emerge that require choosing the most appropriate one as a group), (2) the fact of working in small groups distributes the cognitive difficulty among group members through a division of the workload, (3) from the point of view of the teacher there is a double advantage in this approach: (a) it allows the writing process to be visible, and therefore express the difficulties faced by students, and (b) it provides data on the process followed, which facilitates further discussion about different issues (Castelló, 2002). There are several empirical studies that have highlighted the importance of peer support in the composition process (see the review in Graham \& Perin, 2007).

In light of these prior studies, students receive help from the written guide as well as from their instructor while working in groups during this part of the program. Before starting the task, the instructor emphasizes the importance of using the written guide in order to help orient them while developing their syntheses. Using joint reflection methods, they discuss what process then needs to be followed.

Once the students have begun working, the instructor observes every group and when they deem it to be necessary they stop the process in order to help guide the students. In this way, they can propose the sharing of the ideas that emerged after the activation of prior knowledge, or introduce a concept map developed by one of the groups that can be discussed as a class. For example, when they detect that one of the groups is stuck, they should offer to help them and pose questions or refer them to the guide in order to help them continue in the process.

At this stage, students often have a difficult time making certain decisions regarding how to include their prior knowledge in the synthesis. In this case, the instructor's role is to use questions that encourage self-reflection in order to guide students through the decision making process, such as, "I wonder if this idea that your group member has proposed is related to some piece of information that your group has already selected. If so, you could transform it and integrate it into the text".

One technique that can be useful during these sessions is to have each group evaluate the synthesis written by another group and then return it to the group that so that they can use the other's comments and corrections to improve it. It is important to provide the students with instructions on how to review their peer's papers, such as on the importance of offering alternatives or possible solutions when they detect a problem in the writing. 


\section{Development of the Third Synthesis through Individual Work}

From sessions 10 to 12, a third synthesis is developed, this time the students work individually, however they continue to have the support of the written guide as well as their instructor who helps to orient them.

Our goal is for students to internalize the strategies that they have been working on so that they are able to put them in practice in their day-to-day learning activities. However, it is essential to provide assistance in the moments where difficulties arise.

At this point, the student should be able to make their own decisions in relation to their objectives, although they continue to receive the necessary support during the moments in which they encounter difficulties. The instructor's role in this phase is to observe the performance of students and pay attention to the difficulties that may arise in order to offer help through guiding questions. Moreover, since students in this part of individual practice tend to frequently ask for help, the writing process is intentionally stopped at three specific moments: when students have selected the relevant ideas, when they have completed the concept map and at the end of the task. The reason behind this is to pool together ideas and jointly reflect on the decisions that the students are making. This support encourages the students to correct their own writing process after hearing the process followed by their classmates, including the difficulties that they have encountered. The overall goal here is to guide the decision making process as a group.

Once students have completed the synthesis, a final review is carried out as a group. The instructor asks questions such as, "Have you used an appropriate title?", "Is there a clear overall message?", "Are all relevant ideas included?", "Is it well organized?", "Is there a conclusion?", etc.

\section{Studies Supporting the Effectiveness of Our swsL Program}

In order to test the effectiveness of the $s w s L$ program, three studies with a two-group design (experimental and control) were carried out, evaluating the groups before and after the intervention (see Table 8.2). The control group students worked on the contents using the method traditionally followed by their teachers (readings from the textbook and completion of the subsequent activities related to these texts). In addition to these activities, the experimental group, received the intervention described in the previous sections, which was carried out by the first author of this chapter. The analysis and comparison of their performance on the two synthesis tasks (pre-test and post-test), allowed us to investigate the impact of the program on: (1) the processes of reading and 
TABLE 8.2 Summary of the three studies performed to evaluate the efficacy of the SWSL instruction

\begin{tabular}{llll}
\hline Specific aim(s) & Participants & Design & $\begin{array}{l}\text { Experimental } \\
\text { instruction }\end{array}$ \\
\hline STUDY 1 & & & \\
$\begin{array}{l}\text { To study the } S W S L \text { program's } \\
\text { effect on: students' procedures } \\
\text { and products, and the relation } \\
\text { between both variables and } \\
\text { the teachers' ideas about } \\
\text { reading, writing and the } \\
\text { program }\end{array}$ & $11-12$ years old & $\begin{array}{l}\text { pre-post quasi- } \\
\text { experiment with } \\
\text { control group } \\
\text { (Pilot study) }\end{array}$ & $\begin{array}{l}\text { Eight 6o-minutes } \\
\text { sessions implemented } \\
\text { by the teacher. } \\
\text { Performance of one } \\
\text { synthesis through } \\
\text { modelling, joint and }\end{array}$ \\
\hline
\end{tabular}

\section{STUDY 2}

To explore the $S W S L$ program's impact on procedures, products and learning, and the relation between these three variables and the effect of reading comprehension level and prior knowledge on the benefits derived from the program
Initially, 86 students of 1112 years old. 62 participants completed the full study

pre-post-
maintenance
(eight weeks
after) quasi-
experiment with
control group

Twelve 6o-minutes sessions implemented by the researcher. Performance of three syntheses using one method for each: modelling, joint and individual activity
Control instruction 


$\begin{array}{lcc}\text { - Prior knowledge } & -s w S L \text { program } & -s w S L \text { program-effect on procedures and } \\ \text { and reading } & - \text { History texts } & \text { product-quality (except elaboration criterion) } \\ \text { comprehension } & \text { - Reading } & - \text { More complex procedures (particularly rough } \\ - \text { Pre-post } & \text { comprehension } & \text { draft) associated with better-quality products } \\ \text { procedures } & \text { questionnaire } & - \text { Intervention rated positively by participants } \\ \text { - Pre-post product } & \text { - Prior knowledge } & \\ \text { quality } & \text { questionnaire }\end{array}$

- Prior knowledge
and reading
comprehension
- Pre-post-
maintenance
procedures
- Pre-post-
maintenance
product quality
- Pre-post-
maintenance
degree of content
learning

$-S W S L$ program

- History texts

- Prior knowledge questionnaire

- Reading comprehension questionnaire

- Learning questionnaire (see e-chapterAppendix 2-)
- $S W S L$ program-effect on procedures (except rough draft), product-quality and high-level learning

- Complete maintenance eight weeks later of effects on underlining, elaboration, intratextual integration and high-level learning

- More complex procedures associated with better-quality products and this with greater degree of high-level learning

- Underlining and note-taking, together with pretest product-quality, help to explain variance $(57 \%)$ in product-quality and product-quality helps to explain variance in learning $(13 \%)$
These

studies were implemented for a short period of time, in a specific setting and using a specific set of contents.

$\begin{array}{lc}\text { - Prior knowledge } & -s w S L \text { program } \\ \text { and reading } & - \text { History texts } \\ \text { comprehension } & - \text { Prior knowledge } \\ \text { - Pre-post- } & \text { questionnaire } \\ \text { maintenance } & - \text { Reading } \\ \text { Processes } & \text { comprehension } \\ \text { - Pre-post- } & \text { questionnaire } \\ \text { maintenance } & - \text { Learning } \\ \text { product quality } & \text { questionnaire } \\ \text { - Pre-post- } & \\ \text { maintenance } & \\ \text { degree of content } & \\ \text { learning } & \end{array}$

- $S W S L$ program-effect on processes

- More sophisticated processes associated with more complex procedures (except the rough draft in some cases) and better-quality products, and better-quality products associated with a greater degree of high-level learning.

- The process variables time, translated into interactions and first reading of source texts, together with revision, help to explain variance in product-quality $(74 \%)$ and product-quality helps to explain variance in learning $(15 \%)$ 
writing that the students followed while creating the synthesis and which were reflected in the source texts and the intermediate writings generated by students (specifically, underlining, note taking, and rough draft); (2) the quality of the written products (an example of student product could be found in the e-chapter-Appendix 4-), with the criteria being the degree of selection of the main ideas, elaboration of information, text coherence and cohesion, the integration of ideas from both sources and the degree of sophistication of the title; (3) the degree of content learning at both the surface (locating specific information) and deep level (making inferences and integrating distant information); and (4) the processes activated during the task, specifically the first reading of the source texts, separately or in an integrated way, the interactions (long or short) between the sources and the text in production, and revision. Additionally, the time spent on the task and the number of different reading, writing and revision procedures performed (reading of the source texts, preparation of the rough draft, consultation of the written guide, proofreading of the final product, etc.) were evaluated.

The results of these studies indicate that students who receive this training are able to: (1) write high quality texts in terms of the degree of relevance of the ideas included, the elaboration and organization of the information, the coherence and cohesiveness of the text and the integration of ideas from various sources; (2) use reading and writing procedures when creating a synthesis, such as the creation of drafts, underlining and note taking, which allows them to achieve better results; (3) learn the contents of the topic they have worked on in a meaningful and profound way; and (4) read the source texts seamlessly, return to the sources while preparing their own piece of writing, revise the texts they have produced and use the written guide to regulate their learning (Martínez, 2012; Martínez, Mateos \& Martín, 2011; Martínez, Mateos, Martín \& Rijlaarsdam, 2015).

In all of the studies that have been conducted, the students themselves, as well as their teachers, have evaluated the $S W S L$ instruction in a very positive way in terms of its usefulness and relevance. Concretely, after the intervention, a teacher claimed: "Thanks to this experience all my students have learned a lot. Moreover, I know a little more about the way to teach reading and writing to learn. From now, I am going to use the things learned with the program".

\section{General Discussion and Conclusions Derived from the Studies}

The $S w S L$ program designed to improve the use of reading and writing as learning tools is effective and enables students of 11-12 years old to make better syn- 
theses from two source texts containing complementary information, thereby learning their contents in a more profound and constructive way (Martínez, 2012).

It seems that a number of implications for education can be seen in the application of this intervention. Although many studies have pointed out the intrinsic difficulties in performing synthesis tasks (Mateos \& Solé, 2009; SegevMiller, 2004), the $S w S L$ program described here has shown that specifically teaching how to carry out a synthesis can help students to make better use of reading and writing as instruments in knowledge construction.

In general, the $S W S L$ program, based on the instruction produced by Wray and Lewis (1997), and carried out with other methodological support like the written guide, has positive effects on the processes engaged in by the students, the quality of the texts they write and on their high-level learning.

As already noted, the $S w S L$ intervention has both strong and weak points. It is now time to reflect on these in order to be able to put forth recommendations, or precautions to be taken, in regard to teaching the integrated use of reading and writing to learn.

As noted throughout this chapter, special emphasis was placed on the use of the written guides to foster the students' autonomy with this type of tasks. It is also important to note that such guides should be constructed by encouraging the students themselves to reflect on the process, which was the approach taken in this research. Given the effectiveness of this type of help (Castelló, 2002; Gárate \& Melero, 2004), its use should be encouraged in the educational setting.

Another recommendation is to take into account the need to offer individualized help throughout the entire process. In addition, the transfer of control, which offers students the opportunity to self-regulate their learning, should be carried out in an extremely gradual way in order to prevent the problems that we encountered in our studies.

Various problems arose with the work in groups of four because of the number of pupils in the class. However, the students actively participated and succeeded in producing high-quality written texts in each group. Although this was not an activity they usually performed in the classroom, they were satisfied with it, and therefore it should be used more often. The support provided by means of the guiding questions was of great help and the students themselves requested this type of help during the sessions. This suggests that the students can and want to write collaboratively, but in order for it to be effective, they need help.

Furthermore, most of the students found the transition from collaborative to individual work to be difficult. At first, they expressed a certain amount of con- 
cern, but this gradually diminished thanks to the support that was constantly available. However, the transition from collective to individual work should be more gradual, something that could be remedied by more sessions that involve more group work as well as individual work using the guide.

Although the traditional method of teaching that is usually followed in schools has a positive impact on low level content-learning, the $S W S L$ intervention designed here outperforms it. In light of its efficiency, this specific teaching method should be encouraged in schools.

It is necessary to add, however, that although the findings support the usefulness of the SWSL intervention designed for these studies, caution is still necessary, as it was implemented for a short period of time, in a specific setting and using a specific set of contents. It would be interesting to expand the scope of this research in terms of time, settings and contents, and for the $S W S L$ program to be implemented by the pupils' own teachers in their classes. This last condition would entail the need for extensive, thorough, and ongoing training.

Moreover, when implementing this or any other type of intervention in the classroom, the design should not be followed as a sequence of fixed, inflexible steps, but should be adapted to the particular conditions of each situation. The experience with the implementation of this $S W S L$ program was that the objectives frequently became interwoven with each other, which led to teaching them in a recursive and integrated manner, with the person implementing the $S W S L$ program adapting it to the needs of the students and the context.

One of the most innovative aspects of this intervention has been the integration of different teaching methods (modelling, collaborative writing, the written guide and individual work), which, from our point of view, has been key to obtaining the benefits found. In any case, since there is research showing the effectiveness of each (Harris, Graham \& Mason, 2006; Zimmerman \& Kitsantas, 2002), it would be interesting to investigate whether the integration of these methods or any combination of them is more effective than one of the methods alone.

Finally, one thing that should be considered is that the potential of hybrid tasks to foster critical thinking and learning has not been fully taken advantage of in schools. The $S W S L$ program has contributed fresh evidence on the importance of focusing on teaching such tasks. It is both possible and desirable to encourage students early on to use reading and writing to learn (Wray \& Lewis, 1997). In spite of their teachers' skepticism, the previously mentioned studies have demonstrated the ability of 11-12 years old pupils to successfully perform complex reading-and-writing-to-learn tasks when they are taught to 
do so through suitable methods. In short, it seems useful and pertinent to teach students to synthesize information from various source texts as a way of getting them to make good use of reading and writing.

\section{Appendices}

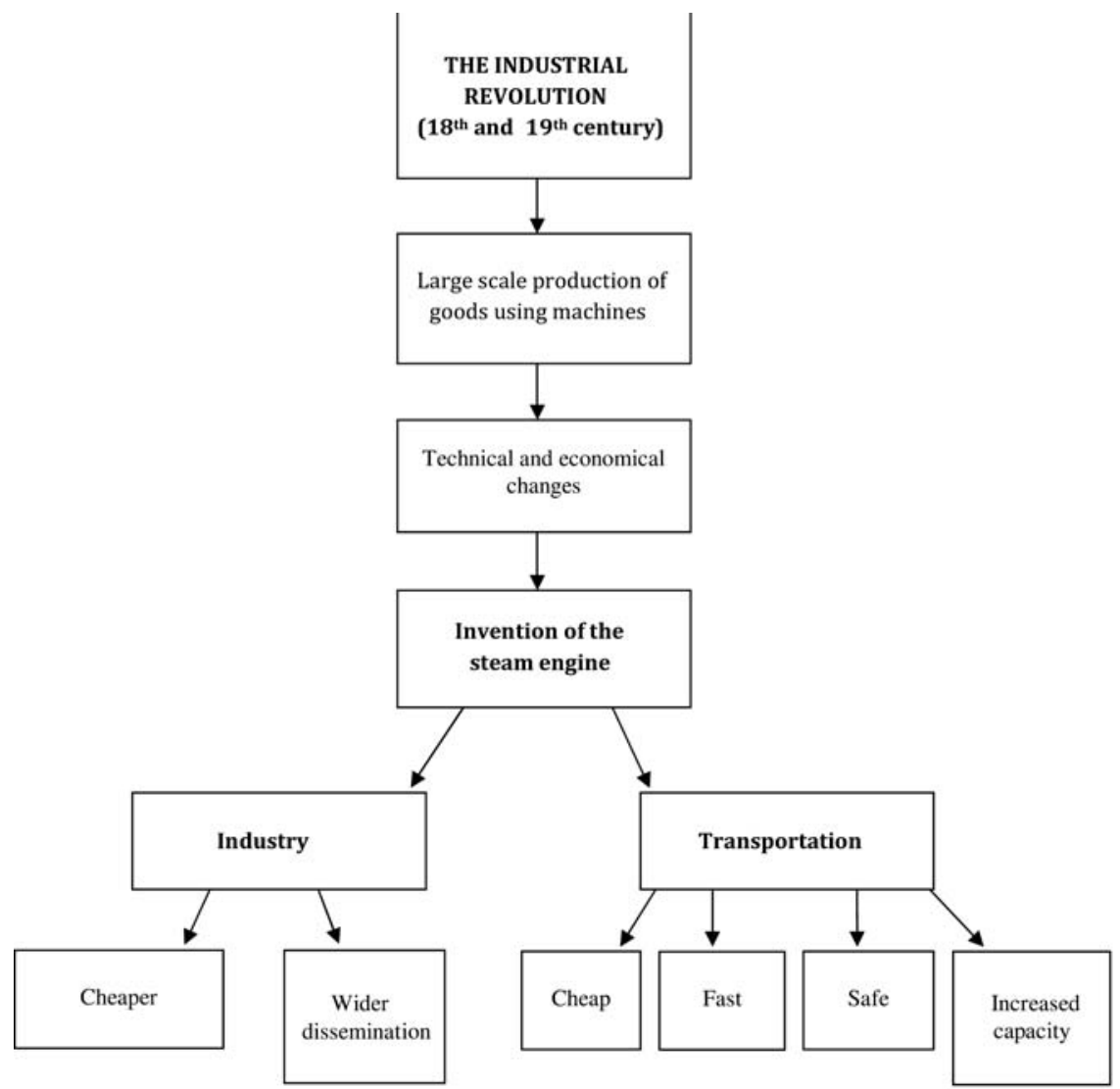

FIGURE 8.1 Example of a concept map created during the intervention 


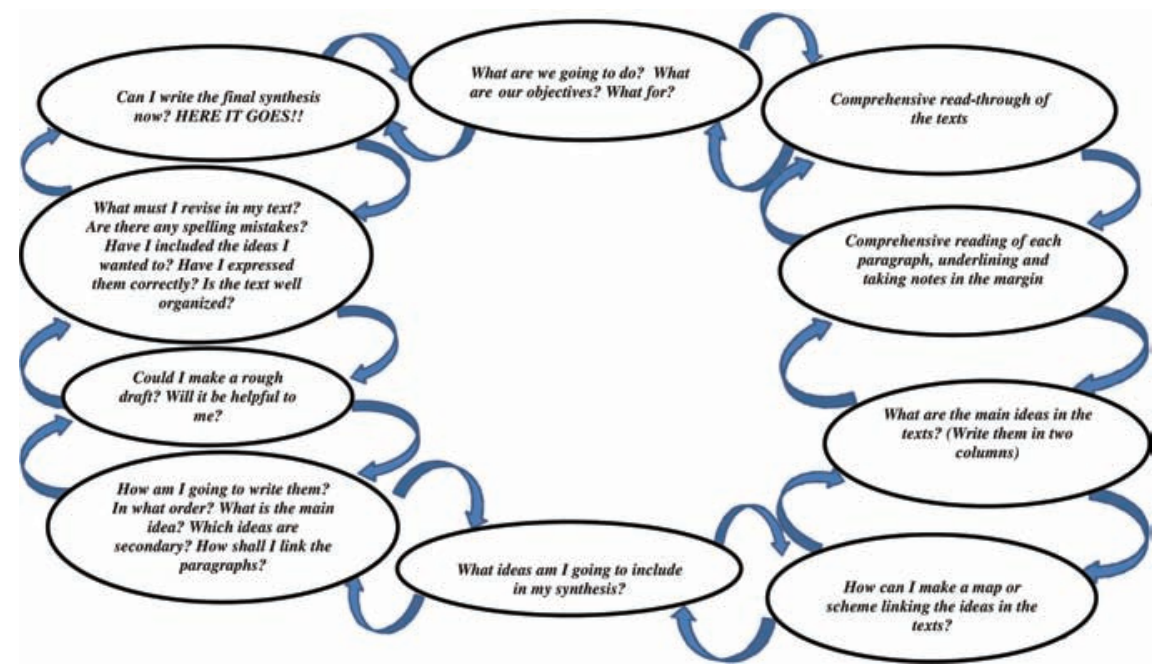

FIGURE 8.2 Guide for carrying out a synthesis 'appendix' replace by 'figure', ok?

\section{References}

Anderson, J.R. (1980). Cognitive psychology and its implications. San Francisco: Freeman. Boscolo, P., Arfé, B., \& Quarisa, M. (2007). Improving the quality of students' academic writing: an intervention study. Studies in Higher Education, 32(4), 419-438.

Braaksma, M.A.H., Rijlaarsdam, G., van den Bergh, H., \& van Hout-Wolters, B.H.A.M. (2004). Observational learning and its effects on the orchestration of writing processes. Cognition and Instruction, 22, 1-36.

Castelló, M. (2002). Las estrategias de aprendizaje en el proceso de composición escrita [Learning strategies in the written composition process]. In C. Monereo (Coord.), Estrategias de aprendizaje [Learning strategies] (2 ${ }^{\mathrm{a}}$ ed.) (pp. 147-184). Madrid: Antonio Machado libros. (Translation from Catalonian to Spanish by Sonia Sánchez Busqués).

Castelló, M. y Milián, M. (1997). Enseñar y aprender estrategias en el proceso de composición escrita [Teach and learn strategies in the written composition process]. In M.L. Pérez Cabaní (Coord.), La enseñanza y el aprendizaje de estrategias desde el currículum [Teaching and learning of strategies from the currículum] (pp. 117-135). Barcelona: Horsori.

Flower, L., Stein, V., Ackerman, J., Kantz, M.J., McCormick, K., \& Peck, W.C. (1990). Reading to write: Exploring a cognitive and social process. New York/Oxford: Oxford University Press.

Gárate, M., y Melero, A. (2004). Teaching how to write argumentative texts at primary 
school. In G. Rijlaarsdam (Serie Ed.) y G. Rijlaarsdam, H. Van den Bergh y M. Couzijn

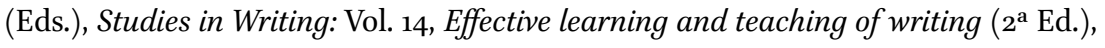
part 2, Studies in how to teach writing (pp. 323-337). Nueva York: Kluwer Academic Publishers.

Graham, S., \& Harris, K.R. (1996). Self-regulation and strategy instruction for students who find writing and learning challenging. In M.C. Levy, \& S. Ransdell (Eds.), The science of writing: Theories, methods, individual differences, and applications (pp. 34736o). Mahwah, NJ: Lawrence Erlbaum Associates.

Graham, S. \& Perin, D. (2007). A Meta-Analysis of Writing Instruction for Adolescent Students. Journal of Educational Psychology, 99, 445-476.

Harris, K.R., Graham, S., y Mason, L. (2006). Improving the writing performance, knowledge and motivation of young struggling writers in second grade. American Educational Research Journal, 43, 295-340.

Martínez, I. (2012). Enseñar a leer y escribir para aprender en la Educación Primaria: Diseño y evaluación de un programa de intervención de escritura de síntesis a partir de varios textos [Teaching reading and writing in order to learn in Primary Education: Design and evaluation of an intervention program for writing a synthesis from various texts]. Dissertation, Autónoma University of Madrid, Madrid, Spain.

Martínez, I., Martín, E., y Mateos, M. (2011). Enseñar a leer y escribir para aprender en la Educación Primaria [Teaching reading and writing to learn in primary education]. Cultura y Educación, 23, 399-414. Mateos, M. (2001). Metacognición y Educación [Metacognition and Education]. Buenos Aires: Aique.

Martínez, I., Mateos, M., Martín, E. \& Rijlaarsdam, G. (2015). Learning history by composing synthesis texts. Effects of an instructional programme on learning, reading and writing processes and text quality. Journal of Writing Research, 7(2), 275-302.

Mateos, M., \& Solé, I. (2009). Synthesising information from various texts: A study of procedures and products at different educational levels. European Journal of Psychology of Education, 24, 435-451.

Pozo, J.I., y Postigo, Y. (2000). Los procedimientos como contenidos escolares: uso estratégico de la información [The procedures as school contents: strategic use of the information]. Barcelona: Edebé.

Raphael, T.E., y Englert, C.S. (1990). Writing and reading: Partners in constructing meaning. The reader Teacher, 43, 388-400.

Risenberg, R. (1996). Reading to write: Self-regulated learning strategies when writing essays from sources. Reading Research and Instruction, 35, 365-383.

Sánchez, E., García, J.R., y Rosales, J. (2010). La lectura en el aula: qué se hace, qué se debe hacery qué se puede hacer [Reading in classroom: what is being done, what should be done and what can be done]. Barcelona: Graó.

Schunk, D.H., \& Zimmerman, B.J. (1997). Social origins of self regulatory competence. Educational Psychologist, 32, 195-208. 
Segev-Miller, R. (2004). Writing from sources: the effect of explicit instruction on college students' processes and products. L1-Educational Studies in Language and Literature, 4, 5-33.

Spivey, N.N., \& King, J.R. (1989) Readers as writers composing from sources. Reading Research Quarterly, 24, 134-173.

Torrance, M., Fidalgo, R., \& García, J. (2007). The teachability and effectiveness of cognitive self-regulation in sixth-grade writers. Learning and Instruction, 17, 265285 .

Vidal-Abarca, E. (2002). Las dificultades de comprensión II: Diagnóstico y tratamiento [Comprehension dificulties II: Diagnostic and treatment]. In A. Miranda and others (Eds.), Evaluación e intervención psicoeducativa en dificultades de aprendizaje [Psychoeducative evaluation and intervention in learning dificulties]. Madrid: Pirámide.

Wray, D., \& Lewis, M. (1997). Extending literacy: Children's reading and writing nonfiction. London: Routledge.

Zimmerman, B.J. (2000). Attaining self-regulation: a social cognitive perspective. In M. Boekaerts, P. Pintrich \& M. Zeidner (Eds.). Handbook of self-regulation (pp. 1339). San Diego, C.A.: Academic Press.

Zimmerman, B.J., y Kitsantas, A. (2002). Acquiring writing revision and self-regulatory skill through observation and emulation. Journal of Educational Psychology, 94, $660-668$. 